Artículo

\title{
La desorganización campesina de los maiceros de Huandacareo Michoacán: razones y trascendencia
}

Gerónimo Barrios Puente ${ }^{1}$

Mariano González López ${ }^{1}$

Dora Ma. Sangerman-Jarquín ${ }^{2}$

Francisco Pérez Soto ${ }^{1}$

Felipe Jerónimo Ascencio ${ }^{1}$

Arisbeth Rosales Hortiales ${ }^{1}$

${ }^{1}$ División de Ciencias Económico-Administrativas-Universidad Autónoma Chapingo. Carretera Federal México-Texcoco km 38.5, Chapingo, Estado de México. CP. 56230. (marianohuanda81@gmail.com; perezsotofco@gmail.com; fjascencio@yahoo.com.mx; arisroho@hotmail.com). ${ }^{2}$ Campo Experimental Valle de México-INIFAP. Carretera los Reyes-Texcoco km 13.5, Coatlinchán, Texcoco, Estado de México, México. CP. 56250. (sangerman.dora@inifap.gob.mx).

Autor para correspondencia: gbarriospuente55@gmail.com.

\section{Resumen}

El maíz es el cereal más investigado de los productos agrícolas en México. En el país, el cultivo se siembra principalmente bajo la modalidad temporal y en el ciclo productivo primavera-verano. El maíz (Zea mays L.) es componente esencial de la dieta de los mexicanos, con un consumo per capita promedio de $120 \mathrm{~kg}$, es por ello que es importante observar las interconexiones que existen entre los productores de maíz y como han contribuido de manera muy importante en primera instancia a la de su familia, comunidad y ámbito regional. La investigación se llevó a cabo en el invierno 2019-2020 en el municipio de Huandacareo, Michoacán. Los objetivos de este trabajo, fue analizar la problemática en materia de organización económica campesina; así como, mostrar los costos de la precaria organización para el productor de maíz. Se realizaron 68 entrevistas semiestructuradas dirigidas a los productores maiceros convencionales, lo que representó $100 \%$ de la muestra. Los resultados muestran que los problemas de las organizaciones campesinas existentes son la relación clientelar, el escaso tiempo de los productores, la demagogia, favoritismos en los apoyos, diferencia de intereses y el minifundio. Asimismo, las barreras que impiden el surgimiento de nuevas organizaciones son la falta de recursos y de una cultura organizativa, envidia, líderes indispuestos, malas experiencias del pasado, política pública incorrecta, poca información y búsqueda de beneficios en corto plazo. Los costos indirectos para el productor de la precaria organización son la compra de insumos caros, venta de productos a precios de mercado, poco asesoramiento técnico y un proceso de adopción de tecnología lento por el escaso uso del crédito.

Palabras clave: asociatividad, organizaciones económicas, productividad.

Recibido: marzo de 2020

Aceptado: julio de 2020 


\section{Introducción}

Debido a la propia naturaleza nutritiva y versátil, el maíz (Zea mays L.) es el alimento básico por excelencia en México (Guerrero y Fiscal, 2015). Las cifras productivas reflejan la importancia del cultivo, este ocupa 37\% del total de la superficie sembrada en México en 2018 (SIAP, 2019). En el país, el cultivo se siembra principalmente bajo la modalidad temporal y en el ciclo productivo primavera- verano (SIAP, 2019). La producción de maíz grano en México se concentra en ocho estados: Sinaloa, Jalisco, Estado de México, Michoacán, Guanajuato, Guerrero, Chiapas y Veracruz (SIAP, 2018).

El maíz grano se produce en dos variedades, la blanca y la amarilla, la primera se utiliza esencialmente para el consumo humano y la segunda se destina para el consumo animal y la industria y es en la cual se registra un déficit. A pesar, de que la producción de maíz en México ha crecido sostenidamente desde 2011, no se alcanza a cubrir la demanda nacional de maíz amarillo, por lo que se ha tenido que importar este producto (SIAP, 2018). La cantidad importada equivale alrededor de $40 \%$ del volumen consumido y es resultado de los bajos niveles de producción interna.

Una de las peculiaridades de la producción de maíz en el estado de Michoacán es la heterogeneidad del rendimiento. En maíz bajo riego las disparidades son marcadas, con diferencias de casi 6.5 t en los distritos con más altos rendimientos y los menos productivos (Toribio y Kelbach Baer, 2017).

González (2017) estimó que en el municipio de Huandacareo se sembró maíz en el ciclo agrícola P-V 2016 en una superficie de 285 ha, de las cuales 225 son en labor de riego y 60 en condiciones de temporal. Se estima que, en el municipio, 140 productores están dedicados a la producción de maíz grano. El rendimiento promedio de maíz grano en labor de riego en 2017 fue de $6.26 \mathrm{t} \mathrm{ha}^{-1}$ (SIAP, 2019).

El maíz es indiscutiblemente el cereal más investigado de los productos agrícolas en México. Es posible afirmar que la mayoría de los estudios de las ciencias sociales sobre el tema incluyen a la vez la dimensión económica, la dimensión política y la dimensión social (Appendini, 2001). Dentro de las investigaciones sobre la dimensión económica del maíz en el municipio de estudio, González (2017) realizó un análisis económico a los diversos sistemas de manejo de maíz basado en trabajo de campo y entrevistas directas semiestructuradas a productores. En esa investigación, se determinó con base en un análisis financiero de cada sistema de manejo de maíz que el alto costo de la renta de maquinaria agrícola y agroinsumos, la elección de germoplasma de baja calidad, el empleo de dosis de fertilización inadecuadas, el arrendamiento de tierras agrícolas, así como el minifundio, representan las principales limitantes de la productividad del maíz.

En esta investigación, una vez que se detectó un problema de productividad en maíz, se decidió profundizar su estudio y buscar cuáles son las causas de esta situación. Una de las principales, es la desorganización campesina de los maiceros del municipio de estudio, un tema de investigación relevante por la escasez de estudios sobre organizaciones económicas agrícolas. En el presente trabajo se examinaron cuáles son las barreras que impiden el crecimiento o el surgimiento de las organizaciones campesinas y como esto impacta en la productividad de la actividad maicera en el municipio de Huandacareo, Michoacán. 
Algunos de los estudios relacionados con la organización campesina tienen como premisa hacer una revisión histórica-contextual de su marco legislativo y de los programas gubernamentales que se implementaron para su impulso o durante su surgimiento. Algunos de ellos son los realizados por Blanca (1996); Bruno-Lutz (2007); Damián-Huato et al. (2008); De Grammont y Mackinlay (2006). Son casi nulas las investigaciones enfocadas en analizar de manera local la problemática de la organización campesina a modo de estudio de caso. Ante este panorama, el objetivo principal fue escudriñar la problemática real en materia de organización campesina de una comunidad maicera típica mexicana y como estos impactan negativamente la productividad del cultivo.

\section{Las organizaciones económicas agrícolas en México}

Las peculiaridades propias del sector rural acrecientan la necesidad que tienen sus habitantes para contar con organizaciones (Gómez, 2017). El movimiento campesino que surgió en la década de los setenta nació enraizado a dos procesos estructurales: la crisis del campesinado y el ascenso del neoliberalismo. Como respuesta los campesinos impulsaron un movimiento que se transformó en la lucha por el territorio, la autogestión productiva y la autonomía. Esta lucha promovió el número de las organizaciones campesinas (Blanca, 1996).

El modelo asociativo persigue la creación de valor a través de la solución de problemas comunes originados fundamentalmente por falta de escala (Liendo y Martínez, 2001). La FAO (2017b) menciona que una organización asociativa es entendida como aquella organización voluntaria y no remunerada de personas o grupos que establecen un vínculo explícito, con el fin de conseguir un objetivo común, monetario o no monetario. Para Robles (2018) los principales tipos de organizaciones económicas, independientemente de su personalidad jurídica, son: cooperativas, uniones, sociedades de solidaridad social (SSS), sociedades de producción rural (SPR), asociaciones agrícolas locales (AAL), grupos de trabajo, federaciones y asociaciones civiles constituidas por organizaciones económicas (FAO, 2017a).

\section{Organizaciones económicas de los productores de maíz en Michoacán}

Las organizaciones económicas del producto maíz en el Estado de Michoacán se enlistan en el Cuadro 1. El principal servicio que ofrecen es el acopio y comercialización del maíz grano, seguido por la venta de insumos, asistencia técnica y financiamiento (créditos productivos). Cabe señalar, que ninguna de estas organizaciones campesinas tiene influencia directa en el municipio de estudio.

\section{Cuadro 1. Organizaciones económicas del producto maíz en Michoacán.}

\begin{tabular}{ll}
\hline Organización & Producto o actividad \\
\hline Agricultores Unidos de Ixtlán, SPR de RL & Maíz y trigo \\
Agricultores Unidos Región Guayangareo, SPR de RL & Maíz \\
Grupo de Innovación Regional Indaparapeo, SPR de RL & Maíz \\
Impulsora Agropecuaria Chavinda, SPR de RL & Maíz \\
Productores Rurales del Bajío, SPR de RL & Maíz \\
Red de mujeres y Campesinos de Michoacán & Maíz \\
Servicios Agropecuarios La Guaracha, SPR de RL & Maíz \\
Sociedad Cooperativa Meseta Purépecha & Maíz y derivados \\
Temascales Los Huisáchales, SPR de RI & Maíz \\
\hline
\end{tabular}

Elaborado con la información de Robles (2018). 
Debido al alcance de esta investigación es complicado medir a ciencia cierta cuál es la trascendencia de cada organización y sus impactos en la productividad del maíz en su zona de influencia. Sin embargo, al conocer las funciones de una organización maicera se vislumbran los beneficios de éstas para los productores agremiados.

\section{Asociaciones campesinas en el municipio}

En la actualidad existen dos organizaciones campesinas en funcionamiento: los ejidos que, aunque no son organizaciones económicas como tal, si son organizaciones voluntarias de personas que persiguen objetivos en común (o sea que se ajustan a la definición de organización) y una asociación de productores ganaderos.

\section{Los ejidos}

Dentro de los límites territoriales del municipio existen seis ejidos: El Jaripal, San Nicolás, La Estancia, San Cristóbal, El Marino y Huandacareo. En total, en los cinco ejidos dentro del municipio existen 708 ha parceladas, de las cuales 551 están destinadas a la actividad agrícola (INEGI, 1999). El INEGI (2009) reporta que 444 ha cuentan con riego y 107 ha de actividad agrícola de temporal. Asimismo, en el municipio están reportados 313 ejidatarios (INEGI, 2007). Como tal, los ejidos no tienen como objetivo principal llevar a cabo acciones que incrementen la productividad agrícola por medio de las economías de escala, más bien fungen como una estructura agraria con funciones meramente burocráticas.

\section{La asociación de productores ganaderos de Huandacareo}

La asociación ganadera como comúnmente se le conoce, es una organización campesina que provee un suministro de agroinsumos a los productores locales a precios competitivos y ayuda en la gestión legal de la actividad ganadera del municipio. Sin embargo, el alcance de esta organización en materia de promoción de la productividad agrícola es bajo, dado que no tiene la solvencia para surtir en tiempo y forma la variedad de agroinsumos que el municipio necesita. Esto provoca que muchos productores los adquieran en otras distribuidoras. No obstante, es innegable que esta asociación contribuye a solventar las necesidades productivas de los maiceros en materia de agroinsumos.

\section{Materiales y métodos}

El municipio de Huandacareo, Michoacán, está situado a $46 \mathrm{~km}$ al noroeste de la capital del estado, comprende una extensión territorial de $95.11 \mathrm{~km}^{2}$. La región hidrológica en la que se encuentra el municipio es Lerma-Santiago. La zona de estudio pertenece a la subregión hidrográfica Lago de Pátzcuaro-Cuitzeo-Laguna de Yuriria (INEGI, 2009).

Una vez delimitada el área de estudio (Figura 1) y haber elaborado y validado en campo el cuestionario para la obtención de la información, se procedió a realizar las entrevistas semiestructuradas dirigidas a productores maiceros convencionales del sitio de estudio mediante un muestreo aleatorio simple. 


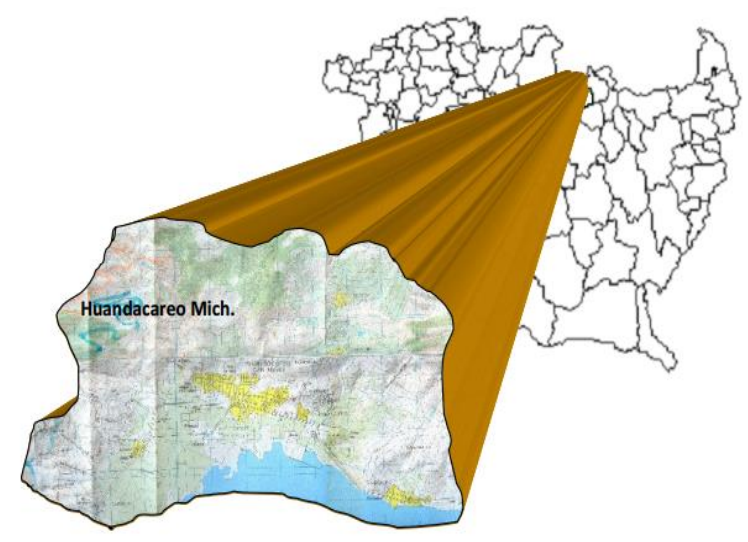

Figura 1. Ubicación geográfica del municipio de Huandacareo, Michoacán.

La ecuación para calcular el tamaño de la muestra fue la siguiente.

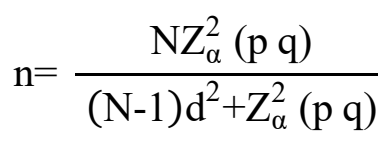

Donde: $\mathrm{n}=$ tamaño de la muestra; $\mathrm{N}=$ tamaño de la población; $\mathrm{d}=$ precisión expresada en porcentaje $(5 \%=0.05) ; Z=$ valor de la distribución $\mathrm{Z}$ con una confiabilidad de $95 \%\left(\mathrm{Z}_{0.05}=1.96\right) ; p=$ probabilidad de éxito $(50 \%=0.5)$ y q= probabilidad de fracaso $(50 \%=0.5)$.

En el presente estudio se encontraron alrededor de 100 productores de maíz grano con un manejo homogéneo, por lo que el tamaño de la muestra quedó definido en 79 productores, de los cuales por cuestiones sanitarias extraordinarias sólo fue factible entrevistar a 68. A cada productor entrevistado que pertenecía a una asociación se le preguntó por sus beneficios y a los que no pertenecían a ninguna se inquirió en las causas de ello. El periodo de levantamiento de las encuestas fue durante el invierno 2019-2020, sin embargo, la información recabada en ellas fue referida al ciclo P-V, 2018-2019.

\section{Resultados y discusión}

Para conocer la idiosincrasia del productor maicero promedio del municipio de estudio, es menester en primera instancia tratar de entender el razonamiento del productor, los orígenes de éste y sus repercusiones en su quehacer diario. Los resultados de campo mostraron que $81 \%$ de los productores no pertenece a ninguna organización campesina y las causas de ello se muestran en la Figura 2. El resto de los productores que si pertenecen a una organización campesina señalan que los principales beneficios que les reporta dicha pertenencia son el acopio, el crédito y los apoyos para la compra de maquinaria e insumos.

En la Figura 2 se vislumbra la problemática actual en materia de organización campesina local para fines de esta investigación se dividió en dos grandes conjuntos, la problemática que presentan las organizaciones campesinas actuales y las barreras que impiden el surgimiento de nuevas organizaciones. El análisis aquí presentado no tiene por objetivo juzgar de cualquier manera a los 
productores locales, sino simplemente mostrar una radiografía actual del tema en discusión. Cabe señalar, que algunos motivos de la desorganización incorporados a la discusión no fueron declarados explícitamente por los productores entrevistados sino más bien estos fueron vislumbrados por el investigador dada su posición de agente externo.

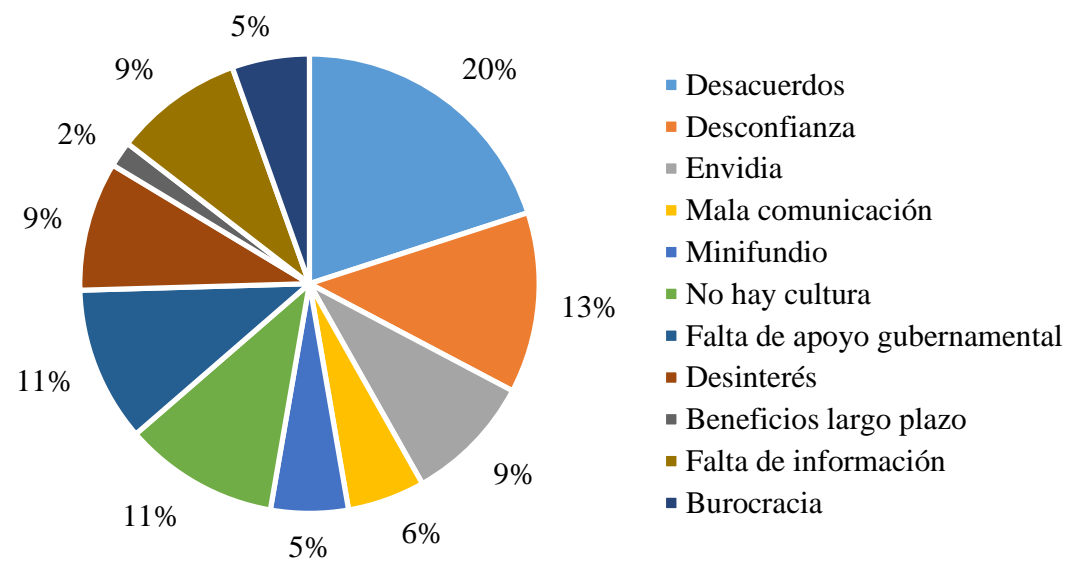

Figura 2. Motivos de la desorganización campesina en el municipio de Huandacareo.

\section{Problemática de las organizaciones actuales}

\section{Relación clientelar}

El proceso de compra típico está formado por la siguiente secuencia de acontecimientos: reconocimiento del problema, búsqueda de información, evaluación de las alternativas, decisión de compra y comportamiento poscompra (Kotler y Keller, 2006). En este último apartado donde radica el problema, ya que los productores maiceros, a lo largo de su trayectoria, han establecido relaciones clientelares en con las pocas organizaciones locales; es decir, solo existe un acercamiento cuando necesitan que se les apoye en la gestión de un problema, al momento en que dicho problema es resuelto abandonan el vínculo con la organización que los apoyó. Esta dinámica, que denominamos clientelar, impide consolidar una relación estable en el largo plazo entre el productor y la organización.

\section{Falta de tiempo de los productores}

Cuando un productor se acerca a una organización en busca de apoyo para la solución de un problema (relación clientelar), necesita invertir una gran cantidad de tiempo para encontrar dicha solución, debido a la ineficiencia burocrática generalizada de las instituciones en México. El productor promedio, tiene una agenda ocupada, ya sea porque está ocupado realizando sus actividades agrícolas o porque tiene otras actividades económicas que atender, viendo limitado su tiempo disponible que puede invertir en la búsqueda de una solución a su problema. El escaso tiempo libre del productor genera que se eleve su costo de oportunidad (Lozano-Rodríguez, 2016), lo que limita las posibilidades de la organización local y genera un desinterés generalizado. 


\section{Demagogia de las organizaciones}

La palabra demagogia sirve para calificar de manera negativa el modo de hacer política de aquel que busca sólo consensos fáciles (Pazé, 2016). Las organizaciones locales, como los ejidos y la asociación ganadera, periódicamente tienen reuniones para discutir la orden del día. La asistencia a ellas no es obligatoria para los productores, sin embargo, aquellos que no asisten argumentan que en dichas reuniones se habla demasiado y se acuerda poco, donde además se cae en la demagogia; es decir, se prometen cosas (que rara vez se cumplen) para llegar a acuerdos fáciles. Estas reuniones son consideradas por muchos productores como un mero formalismo, donde se simula hacer algo productivo para el beneficio común.

\section{Favoritismo en subsidios gubernamentales}

La dinámica de subsidios o apoyos gubernamentales escapan totalmente a los alcances de las organizaciones locales, dado que el recurso de estos proviene del nivel federal y estatal, lo que implica que los lineamientos para poder acceder a los recursos, de igual manera, los establecen las instituciones federales y estatales correspondientes. Así, las organizaciones locales solo fungen como gestoras o facilitadoras de la burocracia. En los lineamientos de los diversos programas se establecen la serie de requisitos necesarios para acceder a los recursos, requisitos que solo satisfacen en su totalidad un número muy limitado de productores año tras año, por lo que en el campesinado permea la idea de que los subsidios llegan a las mismas personas por favoritismo. Esta situación provoca que el productor común y corriente sienta desconfianza hacia las organizaciones y decida no acercarse a estas en busca de ayuda.

\section{Idea de que las organizaciones responden a intereses políticos o personales}

Es difícil escapar a la idea de que una organización, cualquiera que esta sea, responde a ciertos intereses de índole personal o políticos, ya que como menciona Schmitter (1974), la organización social muchas veces se subordina al partido político. De igual manera, cuando existe un conflicto de intereses se dificulta la realización de los deberes que se le otorgan a una persona y se ve reducida su legitimidad frente a la ciudadanía (García-González, 2015). En esta sociedad escasean las personas que ayudan desinteresadamente. Los mismos productores piensan que las organizaciones locales responden a intereses políticos o personales y que, para recibir algún beneficio por el hecho de pertenecer a ella en algún momento tendrás que devolver cualquier favor recibido de alguna manera u otra. El hecho de que los productores perciban a las organizaciones locales de este modo les impide construir una mejor organización.

\section{Producción del maíz en pequeña propiedad privada (minifundio)}

El extinto Banco Nacional Agropecuario (1975) señaló que la explotación minifundista de la tierra representa el principal obstáculo al desarrollo del sector agropecuario. En ese sentido, la mayor parte de la producción de maíz en el municipio de estudio se realiza en terrenos ejidales, sin embargo, una parte importante de la producción se lleva a cabo en pequeña propiedad privada. La producción de maíz en este tipo de tenencia de la tierra genera una especie de aislamiento para los productores propietarios, llevándolos por un camino que sólo busca maximizar su beneficio personal. En los ejidos, existe una comunicación constante entre todos los productores dado que se tienen que tomar decisiones colectivas, por lo que estos productores, además de buscar el beneficio 
personal, también buscan el beneficio colectivo a largo plazo. De esta manera, para fines tocantes a la organización campesina, se argumenta que un productor ejidal tiene más disposición a participar en una organización que fomente el beneficio común que un productor de pequeña propiedad privada, dado que este último no ha experimentado ningún beneficio de la organización.

\section{Barreras que impiden el surgimiento de nuevas organizaciones}

\section{Falta de recursos económicos}

Organizarse tiene costo, el cual nadie está dispuesto a enfrentar en la actualidad. El mayor costo de la organización es el costo de oportunidad o indirecto, debido a que un productor o grupo de productores que tomen la iniciativa de crear una nueva organización deberá o deberán de invertir, mayormente al inicio, una gran cantidad de tiempo y recursos materiales. Hoy, nadie está dispuesto a incurrir en ese costo y nadie quiere sufrir el desgaste físico y emocional de tomar la batuta de iniciar (o al menos intentar iniciar) una nueva organización.

\section{Falta de una cultura organizativa}

La cultura organizacional permite a los miembros de una organización, ciertas conductas e inhibe otras. Cuando esta existe se observa en sus integrantes poca resistencia al cambio y valores compartidos, tales como honestidad, profesionalismo, disciplina y solidaridad, lo que a su vez repercute en una mejor resolución de conflictos (Charón Durive, 2007). La poca asociatividad del municipio se podría explicar en parte porque no existen recursos naturales de uso común salvo el agua de la presa 'San Cristóbal', que se usa para la irrigación del maíz en el municipio de estudio. Para la administración de dicho recurso existe una organización informal de los productores, que surgió debido a la necesidad. En este punto se presume que si existieran más recursos de uso común también existieran más organizaciones campesinas, formales e informales y por lo tanto se podría hablar de una 'cultura' de la organización.

\section{Líderes campesinos indispuestos}

Aquellos que tendrían mayores posibilidades de iniciar una organización campesina nueva son los líderes campesinos locales; sin embargo, existe un problema con ellos: el alto costo de oportunidad de su tiempo dadas sus actividades laborales cotidianas. Por ello es prácticamente imposible que decidan poner de lado su trabajo que les genera ingresos y dedicar parte de su valioso tiempo a una actividad, que como ya se mencionó en los apartados anteriores, les genera cuantiosos costos directos e indirectos. Esta iniciativa por organizarse podría provenir de un agente externo, pero a la fecha no existe una política pública que intente fomentar la organización, además, en el presente trabajo no se vislumbró un interés de los propios productores por organizarse, requisito indispensable para que llegasen a adoptar una figura asociativa, esto de acuerdo con el Banco Nacional Agropecuario (1975).

\section{Envidia}

La RAE define a la envidia como la tristeza o pesar del bien ajeno, o deseo de algo que no se posee. En pocas palabras la envidia es el deseo de obtener algo que posee otra persona y que uno carece, principalmente logros y recompensas. En materia organizativa Jiménez (2016) dice que la envidia 
puede generar una actitud negativa de las personas (indisposición) cuando estas no perciben una situación de equidad. En ese sentido, si la envidia es un sentimiento que permea entre productores maiceros del municipio, cabe la posibilidad de que de antemano tengan la indisposición para ayudarse mutuamente, dado que se perciben en situaciones o realidades diferentes, situación que es perjudicial para la asociatividad campesina.

\section{Malas experiencias en asociaciones personales del pasado}

Para entender el funcionamiento de las organizaciones rurales, hay que dar importancia a las microhistorias y a las relaciones entre personas, familias y grupos (Gómez, 2017). Es común encontrar que grupos de dos o más productores maiceros en algún momento de su vida estuvieron asociados en la búsqueda de beneficios mutuos, ya sea que hayan compartido implementos de maquinaria agrícola, sembrado en conjunto, comprado insumos en conjunto, etc. Sin embargo, la gran mayoría de esas asociaciones personales han fracasado por desacuerdos, derivados de malentendidos económicos, dejando una experiencia nada favorable en la mente de los productores que estuvieron involucrados, razón por la cual sería poco probable que se vieran motivados a iniciar o participar en una nueva asociación, aunque sea de otra índole y con objetivos distintos.

\section{Búsqueda de beneficios en el corto plazo}

La razón fundamental por las que los productores del municipio pudieran algún día organizarse es, en términos prácticos, la búsqueda de beneficios en el corto plazo. Esto se puede explicar con la figura del individuo maximizador racional, ya que esperar beneficios en el largo plazo representa un mayor costo de oportunidad (Lozano-Rodríguez, 2016). Sin embargo, las gestiones de las organizaciones son tardadas, por ese motivo, cualquier organización campesina estaría en condiciones de reportar beneficios a los productores sólo en el mediano y largo plazos. Es justo esa diferencia de intereses en los plazos, una de las principales causas que impide la creación de una nueva organización.

\section{Falta de una política pública que fomente la organización}

La política pública vigente no tiene como objetivo principal impulsar la creación de organizaciones económicas campesinas. Por naturaleza histórica, las organizaciones campesinas locales han nacido de la propia iniciativa de los productores involucrados, donde ellos mismos dan los primeros pasos hacia la organización y una vez que han sentado las bases, buscan algún tipo de asesoramiento en materia organizativa que les permita crecer. Sin embargo, para facilitar este proceso sería necesaria la presencia de una persona que funja como promotor de la organización campesina (agente de cambio) y para ello se requiere indudablemente de la presencia y el apoyo del Estado o en su defecto, de algún mecenas o partido político interesado en la promoción de las organizaciones campesinas locales. De cualquier manera, la idea es que este último absorba en su mayoría el costo de la organización.

\section{Falta de información}

El hecho de que en el municipio no cuente con un agente de cambio, promotor de la asociatividad campesina, genera que el productor promedio no tenga la posibilidad de estar debidamente informado sobre los posibles beneficios de pertenecer a una organización económica campesina 
donde se persigan objetivos comunes. Como ya se mencionó, el hecho de poseer información incompleta o asimétrica reduce las posibilidades de tomar decisiones adecuadas (Varian, 2010). Este elemento es el último eslabón de un círculo vicioso: en primer lugar, no existe un interés generalizado de los productores por organizarse, en segundo lugar, el Estado no tiene como prioridad promover las organizaciones económicas campesinas y, por último, no existe en el municipio un agente de cambio independiente que busque mejorar las condiciones de los productores; a través, de la asociatividad.

\section{No se visualiza la factibilidad}

Todos los puntos anteriores hacen que el productor promedio no considere posible (factible) la creación de una organización, por lo que difícilmente se esforzará en luchar por algo que de antemano cree imposible. Este razonamiento generalizado también podría considerarse como una barrera para la organización campesina, dado que al día de hoy se ha convertido en un prejuicio.

\section{Beneficios y costos de la organización en la producción del maíz}

En este apartado, para el análisis de los beneficios que resultan de la asociatividad se utilizaron los reportados por Quintana (2014). Este autor plantea como principales beneficios de la asociatividad la reducción de costos de producción, las economías de escala en la comercialización y producción, los servicios de asesoría técnica para el incremento de la producción, financiamiento y mejores condiciones de vida de las familias rurales. Por otra parte, los costos de oportunidad para el productor promedio se interpretan como aquellos beneficios que pierde por el hecho de no estar organizado y su importancia radica en que impactan negativamente la productividad maicera (Figura 3) del municipio (Quintana, 2014).

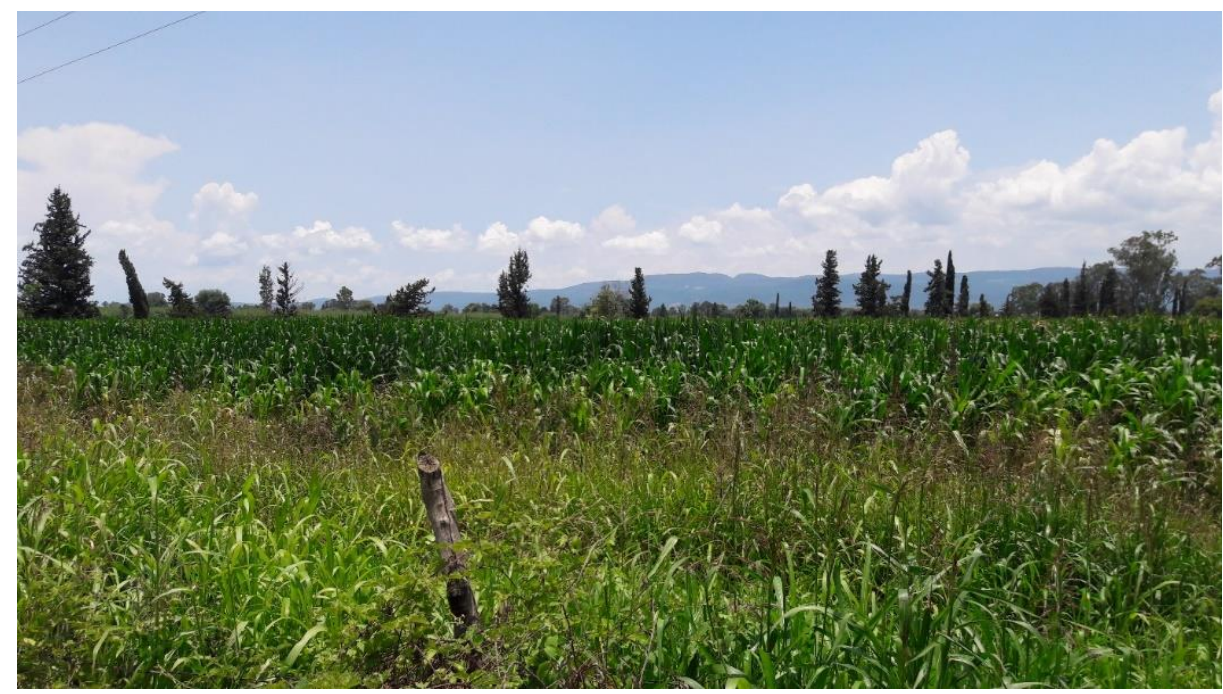

Figura 3. Cultivo de maíz en la zona de estudio.

En esta investigación se hace énfasis en los costos para el productor promedio, ya que es uno de los objetivos que se persiguen y dado que representan la realidad de la actividad maicera hoy. Los beneficios y costos de la organización en la producción de maíz se presentan en el Cuadro 3. 
Cuadro 3. Beneficios y costos de la organización en la producción maicera.

\begin{tabular}{|c|c|c|}
\hline Atributo & Beneficios & Costos de oportunidad \\
\hline Rentabilidad & $\begin{array}{l}\text { Reducción de costos por compra de } \\
\text { agroinsumos a un menor precio, } \\
\text { derivado de la implementación de las } \\
\text { economías de escala }\end{array}$ & $\begin{array}{l}\text { Adquisición de agroinsumos caros, ya } \\
\text { que estos se compran de manera } \\
\text { individual, lo que se traduce en } \\
\text { mayores costos directos de producción } \\
\text { por hectárea y una merma a la } \\
\text { rentabilidad del cultivo }\end{array}$ \\
\hline Ingreso & $\begin{array}{l}\text { Mejor precio de venta dado que la } \\
\text { organización acopia el producto y } \\
\text { existe sólo un canal de } \\
\text { comercialización }\end{array}$ & $\begin{array}{l}\text { Venta del producto a compradores } \\
\text { locales o acaparadores, por lo que el } \\
\text { precio de venta es el de mercado o } \\
\text { inclusive inferior }\end{array}$ \\
\hline Asesoría técnica & $\begin{array}{l}\text { Asesoría técnica suficiente dado que } \\
\text { el gremio contrata regularmente y en } \\
\text { momentos críticos a expertos en maíz }\end{array}$ & $\begin{array}{l}\text { Asesoría técnica insuficiente ya que el } \\
\text { productor promedio no tiene los } \\
\text { medios ni los contactos para para pagar } \\
\text { una asesoría de calidad }\end{array}$ \\
\hline $\begin{array}{l}\text { Adopción de } \\
\text { tecnología }\end{array}$ & $\begin{array}{l}\text { La adopción de nuevas tecnologías es } \\
\text { buena ya que se mantienen en la } \\
\text { vanguardia tecnológica }\end{array}$ & $\begin{array}{l}\text { Adopción de tecnología lenta dado que } \\
\text { cada innovación requiere de un proceso } \\
\text { de validación local, lo cual es un } \\
\text { proceso tardado }\end{array}$ \\
\hline Crédito & $\begin{array}{l}\text { Por medio del crédito que gestiona la } \\
\text { organización campesina los } \\
\text { productores tienen la oportunidad de } \\
\text { comprar insumos de mejor calidad y } \\
\text { de adoptar tecnología innovadora }\end{array}$ & $\begin{array}{l}\text { No existe ninguna organización } \\
\text { campesina que gestione créditos para el } \\
\text { campesino promedio. El crédito } \\
\text { disponible para el productor tiene un } \\
\text { alto costo financiero por lo que le } \\
\text { resulta inaccesible }\end{array}$ \\
\hline $\begin{array}{l}\text { Crecimiento } \\
\text { económico de la } \\
\text { familia rural y el } \\
\text { municipio }\end{array}$ & $\begin{array}{l}\text { Las ganancias que se generan en la } \\
\text { actividad maicera fomentan la } \\
\text { inversión de industrias secundarias y } \\
\text { el consumo local }\end{array}$ & $\begin{array}{l}\text { La rentabilidad del maíz es inestable, } \\
\text { por lo que en ocasiones la economía } \\
\text { local no se beneficia de esta actividad } \\
\text { agrícola }\end{array}$ \\
\hline
\end{tabular}

Elaborado con información de Quintana (2014).

En la columna derecha del Cuadro 3 se observa el listado de costos de oportunidad o beneficios que pierde año con año el productor local promedio, por el simple hecho de no contar con el apoyo de una organización maicera sólida. A continuación, se ahondará en cada uno de ellos.

\section{Compra de insumos caros}

El productor promedio por lo general adquiere sus agroinsumos de manera individual en establecimientos dentro de la misma localidad o cercanos al municipio por diversas razones. En primer lugar, conseguir estos agroinsumos en sitios lejanos resulta poco rentable debido a los costos del traslado y a su bajo volumen de compra, en segundo lugar, el productor maicero local tiene un problema de liquidez y por último, no existe una organización que gestione una compra colectiva para obtener beneficios de las economías de escala, como pudieran ser una reducción de costos y un incremento en la productividad y la eficacia de una empresa, esto de acuerdo con Trujillo (2011). 
Lo anterior, genera que el productor sea incapaz de conseguir precios rebajados. Los establecimientos locales venden los insumos agrícolas a precios de mercado y en muchas ocasiones, como parte de una estrategia comercial, extienden líneas de crédito personales a cada productor de su confianza. Difícilmente el productor de manera individual se verá tentado a romper con esta dinámica y vínculos que, si bien no le reporta beneficios por precio, si lo hace por medio del crédito con intereses nulos.

\section{Venta del producto a compradores locales}

Los compradores de maíz del municipio se podrían dividir en dos grupos, los primeros son simples acaparadores; es decir, aquellas personas cuyo objetivo radica en hacer negocio con la compraventa del producto. El segundo grupo de compradores son aquellas personas que utilizan el maíz como un insumo de otro proceso productivo, principalmente la engorda de ganado bovino y porcino. El problema es que ambos tipos de compradores de maíz utilizan el precio regional de mercado para fijar su precio de compra en la cosecha, el cual varía algunos cientos de pesos en función de la época de cosecha (que va de noviembre a enero generalmente) y entre compradores. En muchas ocasiones son las afinidades personales y las condiciones de pago lo que hace que un productor se decante por un comprador en específico. De acuerdo con Muñoz et al. (2017), cuando no se poseen esquemas adecuados de comercialización, los productores se tornan dependientes del intermediarismo y coyotaje, lo que deriva en bajos precios de venta. El hecho de que cada productor venda su producto de manera aislada y que su mercado sean principalmente acaparadores locales genera que tengan poco poder de negociación, impidiendo así que alcancen un precio de venta competitivo que ayude a mejorar la rentabilidad de su actividad maicera.

\section{Peor asesoramiento técnico}

Una tecnología es una combinación de todas las prácticas de manejo para producir un cultivo (Sangerman-Jarquín et al., 2009). El desarrollo de tecnologías depende de las instituciones y los protagonistas (Albicette-Batreri y Chiappé-Hernández, 2012). En ese sentido, es más factible que una organización de campesinos contrate asesoría técnica experta a que lo haga un productor aislado, lo anterior por un tema meramente de costos. Para el productor aislado, le es incosteable contratar la asesoría de un experto que lo asesore para incrementar su productividad. Por otro lado, el asesoramiento técnico también puede repercutir en la cantidad y calidad de la información que posean los productores sobre los precios a futuro del maíz en la bolsa de Chicago. En economía se asume que cuanta más información posea un agente económico sobre un bien o mercado estará en condiciones de tomar mejores decisiones (Varian, 2010). En ese sentido, los maiceros de Huandacareo, al no contar con una estructura organizacional que les proporcione información confiable sobre los precios futuros de su producto corren el riesgo de tomar decisiones erróneas o basadas en información incompleta o asimétrica.

\section{Adopción de tecnología lenta}

La adopción de tecnología suele ser un proceso lento en el agro mexicano y el municipio de Huandacareo no es la excepción. La teoría de difusión de innovaciones nos dice que la adopción de nueva tecnología es un asunto y una decisión individual, por lo tanto, está afectada por factores de conocimiento, de disponibilidad de recursos económicos y físicos y en gran medida, por la disposición del productor de cambiar parcial o totalmente su forma tradicional de producción (Mendoza, 1987 citado por González, 2004). 
Uddin (2006) refiere a la innovación cuando una idea (conocimiento), se incorpora en la producción. En el municipio de estudio las principales limitantes en materia de adopción de tecnología es la poca disponibilidad de recursos económicos de los productores maiceros, dado que las innovaciones tecnológicas convencionales son costosas, así como la poca disposición de los productores hacia el cambio, ya que en su lógica de producción incorporar una innovación al sistema de manejo del maíz, además de incrementar los costos de producción, también incrementa la incertidumbre, dado que se desconoce la eficiencia de la nueva tecnología incorporada. Lo anterior, genera que el proceso de adopción de las nuevas tecnologías sea lento, que impide estar a la vanguardia tecnológica e impactando en última instancia, la productividad del maíz.

\section{Crédito}

La falta de acceso al crédito formal y a los servicios integrales de intermediación financiera impide el desarrollo agrícola (FAO-GTZ, 2001). El crédito que gestionan algunas organizaciones campesinas ejemplares son una fuente de recursos financieros de bajo costo que los productores utilizan para comprar insumos de la calidad suficiente para transitar hacia un sistema de manejo de maíz de mayor rendimiento. Con este paquete tecnológico se logra incrementar considerablemente, ceteris paribus, la productividad del maíz y por ende, los beneficios económicos de la actividad para el productor. El hecho que el productor promedio no cuente con una fuente confiable de crédito a bajo costo impide la adopción de tecnologías de mayor rendimiento, que repercute negativamente en la rentabilidad de la actividad maicera, poniendo en riesgo su sostenibilidad. En apartados anteriores se mencionó que los productores tienen créditos personales con los distribuidores de agroinsumos locales; sin embargo, no cuentan con el respaldo de alguna organización que les permita adquirir insumos de mejor calidad, es decir, este crédito personal lo utilizan únicamente para adquirir insumos agrícolas de bajo costo y calidad por el temor al sobreendeudamiento.

\section{Reducción del crecimiento económico de la familia rural y el municipio}

El primero y principal beneficiario de una actividad maicera rentable es sin duda el productor y su familia. El segundo gran beneficiario es el municipio. Si por la ausencia de una organización campesina eficiente los productores no tienen las condiciones necesarias para maximizar las ganancias, por el hecho de no poder resolver problemas financieros o técnicos, se estará dejando dinero sobre la mesa -esta frase proviene del mundo del póquer y significa desperdiciar oportunidades de negocio para ganar más dinero, que están ahí pero no son atendidas-, algo perjudicial para la economía del productor y para la economía local y regional. De acuerdo con Johnson y Mellor (1962) la agricultura puede hacer una contribución neta al capital necesario para la inversión fija y el posterior crecimiento de la industria secundaria, jugando un papel importante en el crecimiento económico de una región.

\section{Conclusiones}

El maíz dada su popularidad e importancia permitió describir una problemática organizativa típica mexicana en torno a una actividad agrícola. Es difícil mencionar cuál de todos los problemas explicados fue el más importante dado que todos son relevantes, pero al menos si podemos decir cuál de todos ellos fue el más frecuente en las entrevistas de campo. El problema encontrado con mayor frecuencia fueron desacuerdos entre productores, mismos que tienen un origen en el pasado, pero sus repercusiones permean en la actualidad en forma de un desinterés y una aversión a la organización. Esta situación no exime que existan otras razones psicológicas o sociológicas detrás de los desacuerdos y de las cuales los productores se hayan negado a hablar durante las entrevistas. 
Es complicado también poner en términos monetarios cuáles son los costos indirectos al productor por la precaria organización existentes, ya que para realizar este ejercicio se tendrían que hacer demasiados supuestos. Sin embargo, estos costos impactan negativamente al productor en diversos rubros, como productividad, competitividad, rentabilidad y adopción de tecnología.

\section{Literatura citada}

Albicette-Batreri, M. M. y Chiappé-Hernández, M. 2012. Una experiencia de investigación participativa en Uruguay. Rev. Agric. Soc. Des. 9(1):29-54.

Appendini, K. 2001. De la milpa a los tortibonos. La reestructuración de la política alimentaria en México. 2 (Ed). Centro de Estudios Económicos-El Colegio de México. 290 p.

Banco Nacional Agropecuario. 1975. La organización económica rural. Principios y fundamentos. Banco Nacional Agropecuario, SA. Departamento de Organización Económica de Acreditados. México, DF. 63-78 pp.

Blanca, R. 1996. Las organizaciones independientes en México: opciones campesinas ante el proyecto neoliberal. In: Gramont, H. C. 2002. Neoliberalismo y organización social en el campo mexicano. Plaza y Valdés Editores. 113-163 pp.

Bruno, L. F. H. 2007. Organizaciones de productores de maíz en el Estado de México: papel de las instituciones e importancia de las coyunturas políticas. Universidad Autónoma del Estado de México. México. Ciencia Ergo Sum. 14(2):15-26.

Charón-Durive, L. 2007. Importancia de la cultura organizacional para el desarrollo del sistema de gestión de calidad. Revista Ciencia en su PC. 1(5):87-95.

Damián Huato, M. A.; Valverde, B. R.; Inzunza, F. P.; Paredes Sánchez, J. A.; Muñoz, A. G.; López O. J. F. y León, A. C. 2008. Estrategias de reproducción social de los productores de maíz de Tlaxcala. Rev. de Estudios Sociales. 17(34):111-146.

De Grammont, H. C. y Mackinlay, H. 2006. Las organizaciones sociales campesinas e indígenas frente a los partidos políticos y el Estado. México 1938-2006. Rev. Mex. Sociol. 68(4):78-90.

FAO. 2017a. Asociación de pequeños productores forestales y desarrollo microempresarial. Trigésima reunión. Tegucigalpa, Honduras. 25-29 pp.

FAO. 2017b. Experiencias exitosas de asociatividad de los agricultores familiares en los sistemas agroalimentarios. El caso de la red andina de productores de quinua. Santiago, Chile. 93 p.

FAO-GTZ. 2001. ¿Se justifica el replanteamiento de las finanzas agrícolas? Agricultural Finance Revisited No. 1. Roma. 61 p.

García González, F. 2015. Conflictos de interés en México. Áreas de oportunidad legales y prácticas. Tesis de Maestría en Administración Pública y Políticas Públicas. Tecnológico de Monterrey. 60 p.

Gómez, E. S. 2017. Organizaciones rurales en América Latina (marco para su análisis). Revista Austral de Ciencias Sociales. 1(4):27-54.

González, G. G. 2004. Estrategias de difusión de innovaciones agrícolas en México. Rev. Chapingo Ser. Zonas Áridas. 1(3):73-79.

González, L. M. 2017. Sistemas de manejo, productividad y rentabilidad del cultivo de maíz (Zea mays L.) en Huandacareo, Michoacán, ciclo primavera-verano 2016. Tesis profesional. Departamento de Agroecología. Universidad Autónoma Chapingo (UACH). Chapingo, Estado de México. 123 p. 
Guerrero, J. M. M. y Fiscal, C. B. 2015. Crisis maicera en México. Fondo Editorial Biogénesis. 1(1):19-34.

INEGI. 1999. Tabulados básicos ejidales por municipio. PROCEDE. 1992-1999. Aguascalientes, México.

INEGI. 2007. IX Censo Ejidal. Estados Unidos Mexicanos. Aguascalientes, México.

INEGI. 2009. Prontuario de información geográfica municipal de los Estados Unidos Mexicanos. Huandacareo, Michoacán. Aguascalientes, México.

Jiménez, L. 2016. La envidia en la empresa: de lo que nadie habla. Revista Digital La Vanguardia Noticias. 8 de mayo.

Johnson, B.F. y Mellor, J.W. 1962. El papel de la agricultura en el desarrollo económico. En: Flores Edmundo (1974). Lecturas sobre el desarrollo agrícola. Fondo de Cultura Económica (FCE). México, DF. 469 p.

Kotler, P. y Keller, K. L. 2006. Dirección de marketing. Duodécima edición. Pearson educación. México. 816 p.

Liendo, M. G. y Martínez, A. M. 2001. Asociatividad. Una alternativa para el desarrollo y crecimiento de las PYMES. Universidad Nacional de Rosario. Argentina. Escuela de Economía. Instituto de Investigaciones Científicas. Sexta jornada de ciencias económicas y estadística. 311-319 pp.

Lozano Rodríguez, E. 2016. Teoría y puesta en práctica del análisis económico del derecho colombiano. Primera edición. Facultad de Derecho. Universidad de los Andes. Colombia. $434 \mathrm{p}$.

Muñoz, M. T.; Ocampo, F. I.; Parra, I. F.; Cervantes, V. J.; Argumedo, M. A. y Cruz, R. S. 2017. Proceso de producción y mecanismos de comercialización de chía (Salvia hispanica L.) por familias campesinas de los municipios de Atzitzihuacán y Tochimilco, Puebla, México. Revista Nova Scientia. 9(19):788-818.

Pazé, V. 2016. La demagogia, ayer y hoy. Andamios. Revista de Investigación Social. 13(30):113-132.

Quintana, A. L. 2014. Beneficios de la asociatividad en la pequeña agricultura. Conveagro. III Seminario Internacional de Servicios Financieros Rurales. Lima, Perú. 27 p.

Robles, H. 2018. La organización económica de los pequeños y medianos productores: presente y futuro del campo mexicano. Serie documento de trabajo $\mathrm{N}^{\circ}$ 232. Rimisp, México, DF. 65 p.

Sangerman- Jarquín, D. M.; Espitia, R. E.; Villaseñor, M. H. E.; Ramírez, V. B. y Alberti, M. P. 2009. Estudio de caso del impacto de tecnología en trigo del INIFAP. Rev. Agric. Téc. Méx. 1(35):25-37.

Schmitter, P. C. 1974. Still the century of corporatism? The Review of Politics. 38:85-131.

SIAP. 2018. Atlas agroalimentario 2012-2018. $1^{\text {ra. }}$ edición. Ciudad de México, México. 215 p.

SIAP. 2019. Bases de datos superficie sembrada con el cultivo maíz. http://infosiap.siap.gob.mx/.

Toribio, B. A. y Kelbach, B. N. M. 2017. Las vicisitudes en el diseño de una política pública para el campo: la cruzada estatal por el maíz en Michoacán. In: Garrafa, T. O. M.; Rodríguez, W. C.; Rappo, M. S. E. y García, Z. R. (Coords.). Política pública y territorialidades. Tomo IV. Asociación Mexicana de Estudios Rurales AC. CDMX, México, DF. 107-125 pp.

Trujillo, V. S. 2011. Economías de escala en la agricultura en México: buscando evidencia. Revista Mexicana de Agricultura y de los Recursos Naturales. 6(1):83-102.

Uddin, K. M. 2006. The role of diffusion of innovations for incremental development in small enterprises. Technovation. 26:45-58.

Varian, H. R. 2010. Microeconomía intermedia. Un enfoque actual. Octava edición. Antoni Bosch editor. Barcelona, España. 818 p. 